\title{
Narrative Effects in Russian Indirect Reports and What They Reveal About the Meaning of the Past Tense
}

\author{
Daniel Altshuler \\ Rutgers University
}

\section{The role of reference time in the interpretation of indirect reports}

Ever since the seminal work in (Kamp 1979, Hinrichs 1981; 1986, Kamp and Rohrer 1983, and Partee 1984), it has been generally held that temporal anaphora depends in part on the aspectual distinction between events and states. For example, consider Partee's classic example in (1). Here, the times of the described events (i.e. John's getting up, going to the window, raising the blind, going back to bed) correlate with the order of appearance, i.e. a narrative progression is invoked. On the other hand, the states described in (1) (i.e. being light out, not being ready to face the day, being depressed) hold throughout the described events, i.e. a narrative halt is invoked.

(1) John got up, went to the window, and raised the blind. It was light out. He pulled the blind down and went back to bed. He wasn't ready to face the day. He was too depressed (Partee 1984: 253).

To account for the narrative effects in discourses such as (1), the following has been proposed in the literature on temporal anaphora:

TEMPORAL LOCATION

Whereas the truth conditions for an eventive sentence require that the described event occur within the reference time (i.e. the topical interval of time previously introduced in discourse), the truth conditions for a stative sentence require that the described state hold throughout the reference time (Kamp 1979, Hinrichs 1981; 1986, Kamp and Rohrer 1983, and Partee 1984).

UPDATE OF REFERENCE TIME ${ }^{1}$

An eventive predicate updates the reference time to the duration of the consequent state of the described event (Webber 1988); a stative predicate does not update the reference time (Hinrichs 1981; 1986, and Kamp and Rohrer 1983).

I would like to thank Roger Schwarzschild, Maria Bittner and Matthew Stone for their insight throughout my research on temporal anaphora. Many thanks to Lucas Champollion, Yael Sharvit and Olga Yokoyama for their comments a previous draft of this paper and to Adrian Brasoveanu, Sam Cumming, Angelika Kratzer, Roumi Pancheva, Barbara Partee, Philippe Schlenker, Tim Stowell, and the audiences at the $81^{\text {st }}$ annual meeting of the LSA, CUNY Syntax Supper, SALT 18 and WCCFL 27 for insightful discussions and questions that led to various revisions. I take full responsibility for any errors.

${ }^{1}$ It has also been proposed that eventive predicates updates the reference time to a time "immediately after" the described event and stative predicates update the reference time to the duration of the described state (Partee 1984). As far as I can tell, the generalizations made in this paper do not depend on which version of the rule is chosen. 
REFERENCE TIME RESOLUTION ${ }^{2}$

Unless there exists contextual justification to the contrary, a described eventuality is by default located in time relative to the most recent reference time that is made salient in discourse (after Kamp 1979, Hinrichs 1981; 1986, Kamp and Rohrer 1983, Partee 1984, and Webber 1988).

Let us see how (2)-(4) apply to the discourse in (1). Given (3), the eventive predicate got up updates the reference time to the consequent state of that event. Given the default condition in (4), this is the reference time relative to which the going to the window event is located in time. Finally, given (2), the going to the window event is contained within the consequent state of the getting up event. Applying the rules in this way, we also derive that the raising the blind event is contained within the consequent state of the going to the window event. On the other hand, the state of being light out contains (rather than being contained within) the consequent state of the raising the blind event given (2) and the default condition in (4). Moreover, since stative predicates do not update the reference time, the pulling the blind down event is contained within the consequent state of the raising the blind event given (2) and the default condition in (4) - and so on; see Fig. 1, where the underscore lines represent the consequent state of a described event.

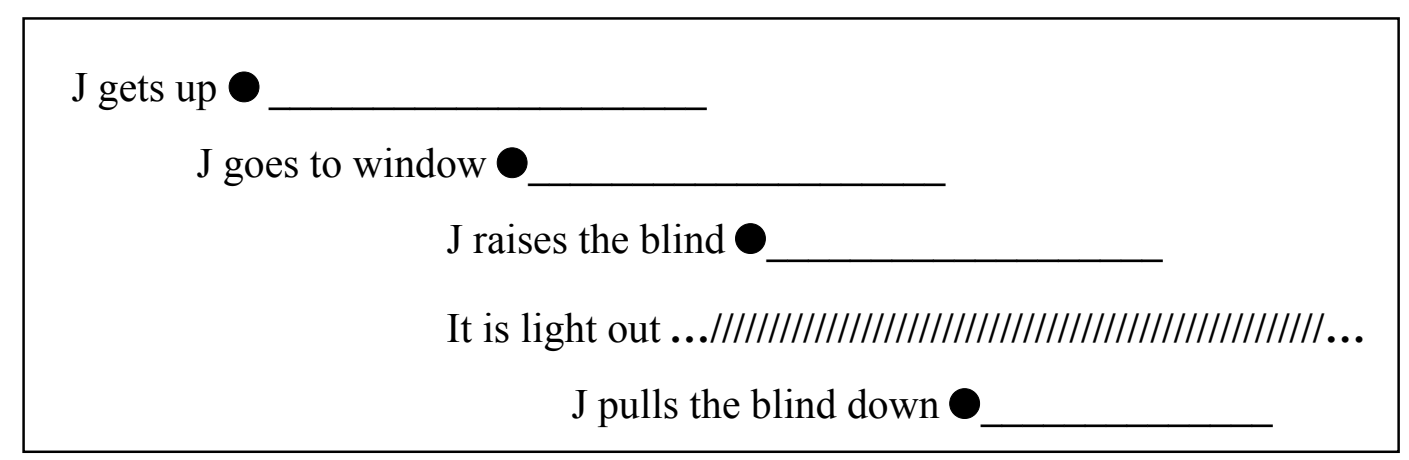

Figure 1: Narrative effects in (1)

The goal of this paper is to investigate narrative effects in indirect reports. These constructions consist of a matrix clause that contains an indirect speech or an attitude verb which describes an eventuality $v_{1}$ and a complement clause that contains a predicate which describes an eventuality $v_{2}$. These eventualities could be ordered in the following way: $v_{2}$ overlaps/precedes/follows $v_{l}$. I argue that (2)-(4) play a crucial role in the temporal ordering of $v_{1}$ and $v_{2}$ analogous to unembedded eventualities in discourse viz. (1). Although the core data comes from Russian, the generalizations made in this paper presumably apply to other languages as well. Russian is chosen for two reasons: (i) the morphological marking on the verb (i.e. perfective 'PFV' or imperfective 'IPF') makes it easy to tell whether the predicate is eventive or stative and (ii) I would like to address the following question, which has not received a satisfactory answer in the literature: when do Russian indirect reports have a reading in which the eventualities described by the embedded and the matrix predicate overlap in time (henceforth: overlapping reading)?

\footnotetext{
${ }^{2}$ This rule is not meant to capture the complex nature of reference time resolution. It merely states a default condition that may be overridden.
} 
Let us begin our investigation by considering the indirect report in (5b), which entails that the eventualities described by the matrix and the embedded clause overlap in time.
a. V prošlom godu, $v$ bare, ja do-li-l
bakal Dudkina $i$
In last year at bar I PFV-pour-PST.1s glass Dudkin and 'Last year, at a bar, I filled up Dudkin's glass and
b. skaza-l, čto ja xote-l eтu soobščit' čto-to prijatnoe.

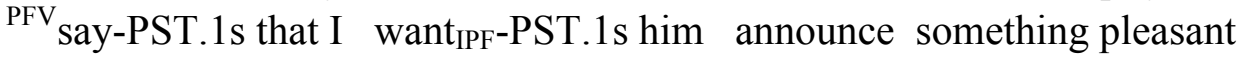 said that I wanted to inform him of something pleasant.'

Given (3), the reference time in (5a) is updated to the consequent state of Dudkin filling up his glass. Given the default condition in (4), this is the reference time in the matrix clause of (5b). What about the reference time in the embedded clause? Let us assume for the sake of illustration that the consequent state of the speaker filling up Dudkin's glass is also the reference time in the embedded clause of (5b). Given (2), the saying event holds within this consequent state and the wanting to inform state holds throughout it. As result it is correctly predicted that (5b) entails that the eventualities described by the matrix and the embedded clause overlap in time:

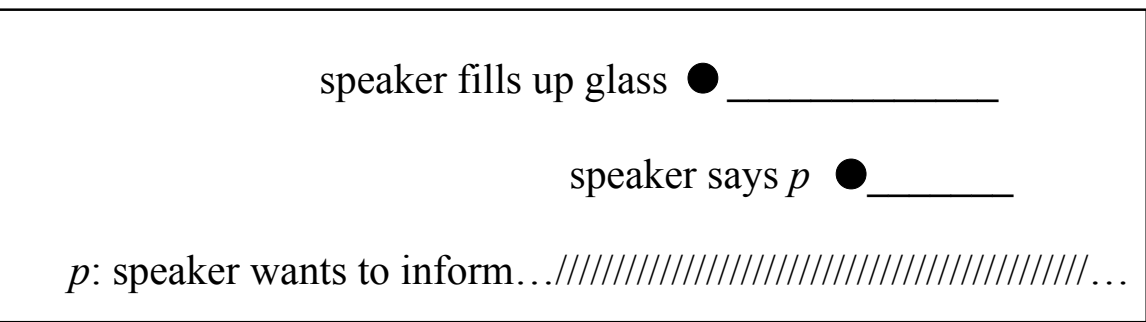

Figure 2: Narrative effects in (5) trigger an overlapping reading

In deriving the overlapping reading, I assumed that the default condition in (4) was overridden: the embedded predicate "disregards" the reference time update of the eventive matrix verb in (5b) and "chooses" the reference time that is updated by a preceding eventive predicate in (5a). This override is necessary since we understand the wanting to inform state to hold before the filling up the glass event (and continuing to hold throughout this event). In fact, it seems that an eventuality described by a past tense predicate embedded in an indirect report can never be located in time relative to a reference time that is updated by an indirect speech (or attitude) verb. This generalization (henceforth Embedded Reference Time generalization or ERT) is perhaps best illustrated by indirect reports with embedded eventive predicates such as the one in (6). If we assumed that the falling in love event was contained within the consequent state of the telling event, Abelard's original utterance would have to have been something like: I will fall in love with another woman.

(6) Abelard told Heloise that he fell in love with another woman. 
The question then, is: how do we account for ERT? One hypothesis would be to say that the past tense on the embedded predicate overrides the default condition in (4); it ensures that the reference time in the embedded clause precedes the time of the event described by the matrix clause. This hypothesis is addressed in $\S 3$. For the time being I will assume that we can identify the reference time in the embedded clause of an indirect report based on our intuitions about the temporal ordering of events-e.g. we know that the consequent state of the speaker filling up Dudkin's glass is the reference time in the embedded clause of (5b) since we understand the wanting to inform state to hold before the filling up the glass event (and continuing to hold throughout this event).

Let us now consider the indirect report in (7b), which is identical to (5b) but has a different interpretation due to the surrounding discourse. Here, an overlapping reading is not entailed (though it is compatible with $7 \mathrm{~b}$ ) - e.g. Dudkin's desire to inform the speaker of something pleasant may never have ceased or this desire may have ceased shortly before the time of his report.
a. V̌era
menja sprosi-l
Lev: "Počemu ty reši-l
Yesterday me
PFV ask-PST.3s Lev why
you decide-PST.2s ${ }^{\text {PFV }}$ go.INF
v bar s Dudkinom?"
to bar with Dudkin
'Yesterday Lev asked me: "Why did you decide to go to the bar with Dudkin.",
b. Ja skaza-l, čto jaxote-l emu soobščit’ čto-to prijatnoe.

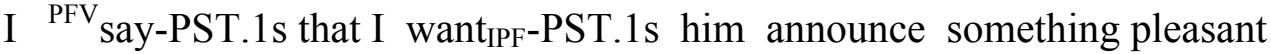
'I said that I wanted to inform him of something pleasant.'

Given (3), the reference time in (7a) is first updated to the consequent state of the speaker's asking, then to the consequent state of Dudkin's decision. However, the saying event in (7b) is understood to be located in time relative to the former consequent state, not the latter. After all, answers follow rather than precede the question to which they correspond to. For example, consider the discourse in (8). Here, Obama's reply is understood to follow the question asking rather than the havoc raising.

The reporter asked a provoking question to Obama. It raised havoc all around the country. I wonder why. After all, the candidate replied as best as he could.

Therefore, I assume that the reference time in the matrix clause of (7b) is resolved to the consequent state of the speaker's asking in (7a) due to extra-linguistic reasoning analogous to (8). What about the reference time in the embedded clause of (7b)? Since we understand the wanting state to precede the decision to go to the bar (and continue to hold throughout this event), the reference time in the embedded clause of (7b) is the consequent state of Dudkin's decision. Given (2), the saying event thus holds within the consequent state of the speaker's asking, while the wanting to inform state holds throughout the consequent state of Dudkin's decision. As result, it is correctly predicted that ( $7 b$ ) does not entail that the eventualities described by the matrix and the embedded clause overlap in time: 


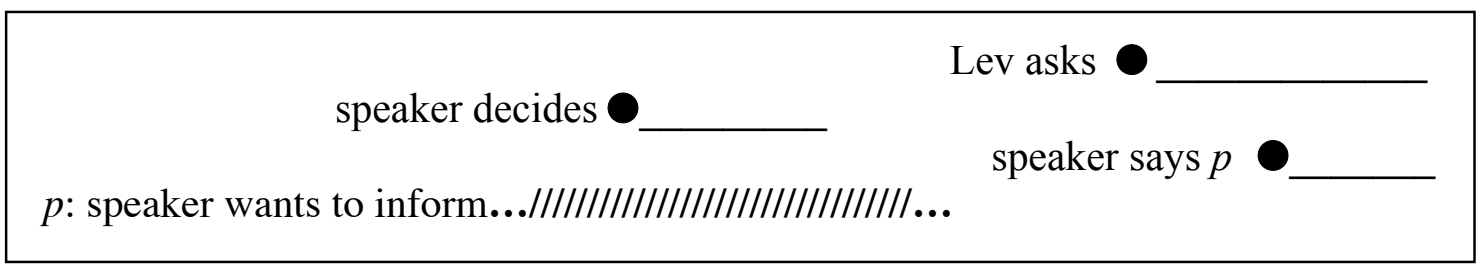

Figure 3: Narrative effects in (7) do not trigger an overlapping reading

In sum, we have seen that when the reference time in the embedded clause of an indirect report overlaps the time of the matrix eventuality, an overlapping reading is entailed. This generalization automatically follows from (2). However, it is quite different from what is has been proposed in the literature on Russian indirect reports. Previous researchers have addressed the question of what allows an embedded eventuality to overlap in time with a matrix eventuality by appealing to properties of grammatical elements such as tense, aspect and verb. In the next section, I attempt to show how some of the previous generalizations - although incorrect-raise some interesting questions about the temporal interpretation of indirect reports that require further research. Subsequently, in $\$ 3$, I consider what narrative effects in indirect reports reveal about the meaning of the past tense. I present novel data and argue that a theory which holds that the past tense requires a reference time to precede the local evaluation time (henceforth Standard Theory) cannot be right if by "reference time" we mean the topical interval of time previously introduced in discourse that accounts for narrative progression. Moreover, I argue that a theory of tense that assumes a richer ontology of times - such as the one in Kamp and Reyle 1993 - could be extended to account for the indirect report data that the Standard Theory cannot.

\section{Previous research on Russian indirect reports}

Forbes (1914) argued that Russian indirect reports allow an overlapping reading only if embedded tense is non-past. This generalization has independently resurfaced in much of the literature on this topic (e.g., Comrie 1985; 1986, Kondrashova 1998; 2006, Kusumoto 1999, Schlenker 2003; 2004, von Stechow 2003, and Babyonyshev and Matushansky 2006). While this generalization is false (see 5 and data in §5), it is surprising that so many researchers have concluded from indirect reports that are similar to those provided in the previous section - albeit without a supporting context - that an overlapping reading is not possible with the embedded past tense. The question then, is: what (if anything) does this reveal about the temporal properties of these constructions? A natural hypothesis is to say that by default, the reference time in the embedded clause of an indirect report precedes the reference time in matrix clause. This hypothesis, along with the implicative nature of the past tense, could possibly explain why past researchers have (incorrectly) generalized from out-of-the-blue indirect reports that an overlapping reading is not possible with the embedded past tense. Future research will hopefully shed light on whether such a hypothesis is correct. 
In contrast to the aforementioned researchers, Khomitsevich (2008) argues that an overlapping reading is possible only if the embedded predicate is imperfective. ${ }^{3}$ However, Khomitsevich does not say why only the imperfective should allow an overlapping reading and why an overlapping reading is often not possible with this aspect (viz. 7). Moreover, as illustrated below in (10), which is an indirect report of (9c), an overlapping reading is, in fact, possible with an embedded perfective predicate when it recieves a habitual interpretation; see also (11), where Alexey's habit of never giving in is understood to hold (though need not be instantiated) at the time of the knowing.
a. $\quad$ Akter (Krivomu Zobu): $\quad$ Valetom xod-i... valetom, čert! Actor (Crooked Goiter): Jack go.IMP jack, devil 'Actor (to Crooked Goiter): Play your Jack...your Jack, dammit!'

b. Baron: A u nas-korol'.

Baron: But to us king 'Baron: And we play the king.'

c. Klě̌č: Oni vsegda po-b'-jut.

Klesh: They always PFV-win-NPST.3p

'Klesh: They always win.'

d. Satin: Takaja u nas privyčka.

Satin: This to us habit 'Satin: We make it our habit...' (Gor'kij, Na dne; Forsyth 1970: 175)

Klešč skaza-l, čto oni vsegda po-b’-jut.

Klesh ${ }^{\text {PFV }}$ say-PST.3s that they always PFV-win-NPST.3p

'Klesh said that they always win.'

(11) Ona zna-l-a, čto v situacijax, sxodnyx $s \quad$ segodnjašnej,

She know IPF-PST.3s-FEM that in situations prevailing from today

Aleksej nikogda ne ustup-it.

Alexey never not ${ }^{\mathrm{PFV}}$ give.in-NPST.3s

'She knew that in such situations as that prevailing today, Aleksey never gave in.' (Aksenov, Kollegi; Forsyth 1970: 178)

That data above reveal that the imperfective is not a suffient or a necessary condition for an overlapping reading. This is not surprising if we assume following Bittner 2007; 2008 that analogous to stative sentences, the truth conditions for a habitual sentence require that the described habit contain the reference time.

Finally, it is worthwhile to note that Boeck (1957; 1958) and Costello 1960/1) have argued that Russian indirect reports with an embedded past tense allow an overlapping reading as long as the matrix verb is an attitude as opposed to an indirect speech verb. These authors conclude that it is not the tense or the aspect of the embedded predicate that is responsible for an overlapping reading (or the lack thereof), but rather

\footnotetext{
${ }^{3}$ This conclusion is independently reached for indirect reports in Romance (see Giorgi and Pianesi 1997; 2000 for Italian and Gennari 2001 for Spanish).
} 
the semantic properties of matrix verb. ${ }^{4}$ While their generalization is also false (see 5 and data in §5), it is again surprising that it was based on indirect reports that are similar to those provided in the previous section. Although it less clear what (if anything) their generalization reveals about the temporal properties of indirect reports, it may be relevant to note that it has been argued that attitude and indirect speech reports have different anaphoric properties. For example, Brasoveanu and Farkas (2007) discuss the differences between say reports and belief attributions. They provide the contrasts in (13) and (15), where (13) is assumed to be based solely on John's statement in (12) and on the assumption that Susan is a student in the class mentioned by John, while (15) is assumed to be based solely on Sam's statement in (14):

(12) John: Everybody in the class understood the notion of presupposition.

(13) a. Mary: John believes that Susan understood the notion of presupposition.

b. Mary: \#John said yesterday that Susan understood the notion of presupposition.

(14) Sam: Mary stopped smoking.

(15) a. Sue: Sam believes that Mary used to smoke.

b. Sue: \#Sam said that Mary used to smoke (and the she stopped).

Brasoveanu and Farkas argue that an explanation of the contrasts above can be reduced to the different ways in which say reports and belief attributions can be true. Unlike say reports, belief attributions do not require there to be an assertive speech act performed by the referent of the subject of the indirect report. This is because "evidence of other people's beliefs is necessarily indirect. Thus, there are many possible grounds for inferring what the beliefs of an agent are: the agent's assertions, her questions/commands as well as her nonlinguistic actions" (Brasoveanu and Farkas 2007:10). Unfortuantely, Brasoveanu and Farkas do not disscuss whether the observed differences between say reports and belief attributions play a role in the temporal interpretation of indirect reports. Future research will hopefully shed light on this question.

\section{The role of the past tense in the interpretation of indirect reports}

\subsection{Predictions of the Standard Theory}

In this section I would like to consider what the Standard Theory of tense-which says that the past tense requires a reference time to precede the local evaluation time - predicts about indirect reports like (16b), which crucially differ from $(5 b) /(7 b)$ in that the embedded predicate is eventive (cf. the perfective marking on the embedded verb):

\footnotetext{
${ }^{4}$ See also Forsyth 1970, Brecht 1975, Barensten 1996, Altshuler 2004, and Khomitsevich 2008.
} 

a. Dudkin soverši-l
ubijstvo $v$ tom zdanii.
Dudkin ${ }^{\text {PFV }}$ committ-PST.3s murder in that building
'Dudkin committed murder in that building.'
b. Mne Anja skazala, čto on y-beža-l s aktrisoj.
Me Anna ${ }^{\text {PFV }}$ say-PST.3s that he PFV-run-PST.3s with actress
'Anna told me that he ran away with an actress.'

Given (3), the reference time in (16a) is updated to the consequent state of the murder. Given the default condition in (4), this is the reference time in the matrix clause of (16b). This is also the reference time in the embedded clause of (16b) since we understand the running away event to follow the murder described in (16a). Given (2), the saying and the running away events are contained in the consequent state of the murder. But how do we account for the intuition that the running away event precedes the saying event?

In order to see what the Standard Theory predicts, let us assume that the tenseless sentence on ubegat' ('he run away') is translated as in (17) and the past tense has the translation in (18). Note that I adopt the following conventions: (i) $\tau$ is a trace function assigning to eventualities in its domain their running time (Link 1987), (ii) $t_{0}$ refers to the speech time when free, or the attitude holder's now when bound by the complementizer (Abusch 1997, Heim 1994, and von Stechow 1995; 2003) and (iii) a free time variable $t_{R}{ }^{\mathrm{n}}$ refers to a reference time $r$, which is a topical interval of time inherited from the context in which the sentence is interpreted.

$$
\begin{array}{ll}
\text { on ubegat' } & \leadsto \lambda t_{1} \lambda w_{l}\left[\exists e_{I}\left[\text { run.away }(h e)\left(e_{1}\right)\left(w_{1}\right) \wedge \tau\left(e_{1}\right) \subseteq t_{l}\right]\right] \\
\mathrm{PST}^{1} & \leadsto \lambda R_{\mathrm{i}_{0}} \lambda w_{1}\left[t_{R}{ }^{1}<t_{0} \wedge R\left(t_{R}{ }^{1}\right)\left(w_{1}\right)\right]
\end{array}
$$

Let us assume for the sake of illustration that the past tense is deictic in embedded contexts, i.e. $t_{0}$ refers to the speech time. Assuming that indirect speech verbs are fourplace predicate requiring a proposition (a set of worlds), an individual term, an event and a world, the indirect report in (16b) would have the following translation:

$$
\begin{aligned}
& \mathrm{PST}^{1} \text { Anja skazat' čto } \mathrm{PST}^{2} \text { on ubegat' } \leadsto \\
& \lambda w_{1}\left[\exists e _ { 1 } \left[t_{R}{ }^{1}<t_{0} \wedge \operatorname{say}\left(\lambda w _ { 2 } \left[\exists e _ { 2 } \left[t_{R}^{2}<t_{0} \wedge \operatorname{run} \text {.away }(h e)\left(e_{2}\right)\left(w_{2}\right)\right.\right.\right.\right.\right. \\
& \left.\left.\left.\left.\left.\wedge \tau\left(e_{2}\right) \subseteq t_{R}^{2}\right]\right]\right)(\text { anna })\left(e_{1}\right)\left(w_{1}\right) \wedge \tau\left(e_{1}\right) \subseteq t_{R}^{1}\right]\right]
\end{aligned}
$$

The reference time variables $t_{R}{ }^{1}$ and $t_{R}{ }^{2}$ in (19) could refer to the same or different reference times depending on the surrounding discourse. Assuming that that they get assigned the same value, an overlapping reading is wrongly predicted to be possible; Fig. 4 illustrates a temporal ordering of events that is compatible with (19). ${ }^{5}$

\footnotetext{
${ }^{5}$ Note that (19) also does not rule out a forward-shifted interpretation in (16b) on which the running away event follows the saying event. Abusch (1997) rules out such an interpretation by proposing the Upper Limit Constraint (see Abusch 1997: 23-25).
} 


\section{Dudkin commits murder}

\section{Anna says $p$ \\ $p$ : Dudkin runs away}

Figure 4: possible temporal ordering of events given (19)

Note that it has been argued by Kusumoto (1999; 2005) that in English, an overlapping reading is possible when the embedded predicate is eventive. If such were the case, then presumably the temporal ordering in Fig. 4 would be a welcomed result. ${ }^{6}$ Kusumoto provides the example in (20) and observes that it can correspond to the direct speech report "Ichiro strikes out", as uttered by an announcer.

(20) The announcer said that Ichiro struck out (Kusumoto 2005: 324).

Note, however, that when an announcer reports live sporting events, he typically uses the present tense so that the sports fan perceives the described event as "ongoing" even though it has already taken place-e.g. when an announcer says "Ichiro strikes out", he says this after Ichiro's bat has gone through the strike zone (i.e. what he really means is "Ichiro has just struck out"). After all, a striking out event is instantaneous and it is not clear how an announcer could report such an event while it is taking place (no matter how fast he is able to talk). ${ }^{7}$

To the best of my knowledge, there are no convincing cases where an overlapping reading is possible when the embedded predicate is eventive (see Gennari 2003 where this point is also made). This is especially clear in Russian, where an episodic perfective predicate in the embedded clause of an indirect report never allows an overlapping reading. Based on this observation, Khomitsevich 2008 proposes that when a Russian indirect report does not entail an overlapping reading, the embedded past tense is bound, i.e. $t_{0}$ refers to the attitude holder's now rather than the speech time. On this view, the indirect report in (16b) would have the following translation, where the propositional argument of skazat' ('say') is now a set of world-time pairs (rather than a set of worlds):

$$
\begin{aligned}
& \mathrm{PST}^{1} \text { Anja skazat' čto } \mathrm{PST}^{2} \text { on ubegat' } \sim \\
& \begin{array}{l}
\lambda w_{1}\left[\exists e _ { 1 } \left[t_{R}{ }^{1}<t_{0} \wedge \operatorname{say}\left(\lambda w _ { 2 } \lambda t _ { 0 } \left[\exists e _ { 2 } \left[t_{R}{ }^{2}<t_{0} \wedge \text { run.away }(h e)\left(e_{2}\right)\left(w_{2}\right)\right.\right.\right.\right.\right. \\
\left.\left.\left.\left.\left.\wedge \tau\left(e_{2}\right) \subseteq t_{R}{ }^{2}\right]\right]\right)(\text { anna })\left(e_{1}\right)\left(w_{1}\right) \wedge \tau\left(e_{1}\right) \subseteq t_{R}{ }^{1}\right]\right]
\end{array}
\end{aligned}
$$

\footnotetext{
${ }^{6}$ Though of course one would still need to explain why the overlapping reading is not possible in (16b).

${ }^{7}$ One may be inclined to conclude that the temporal ordering of events in Fig. 4 is ruled out precisely because the embedded predicate describes an instant. However, not all eventive predicates describe instants (e.g. accomplishment and activity predicates) and in cases where they do not, the intuitions about the temporal ordering of events remain the same (see Gennari 2003 for more discussion of this point).
} 
Assuming that the lexical semantics of an indirect speech (or attitude) verb ensures that time of the attitude holder's report in the actual world is identified with the attitude holder's now in some possible world ${ }^{8}$, an advantage of (21) over (19) is that it ensures that the reference time in the embedded clause precedes the time of the event described by the matrix clause and thereby accounts for ERT, i.e. the generalization that a past tense predicate embedded in an indirect report can never be located in time relative to a reference time that is updated by an indirect speech (or attitude) verb. This welcomed result, however, comes with a cost: since the saying event holds within the reference time denoted by $t_{R}{ }^{1}$, while the reference time denoted by $t_{R}{ }^{2}$ precedes the attitude holder's now, filling in the same value for $t_{R}{ }^{1}$ and $t_{R}{ }^{2}$ leads to a contradiction. Assuming that the identity of these reference times is necessary to account for the intuition that the saying event and the running away event in (16b) follow the murder described in (16a), I take this to be evidence that the Standard Theory cannot be maintained.

One could, of course, question this assumption. However, in doing so, one must then be able to account for the temporal ordering of events described in (16b) relative to the event described in (16a). Instead of trying to rescue the Standard Theory in this way (which is a non-trivial task), I believe it is more fruitful to consider why this theory fails to account for (16b). Its failure seems to be due to the fact that the reference is being asked to do too many things at once-not only is it being asked to account for narrative progression, but it is also being asked to locate the described eventuality relative to the local evaluation time (albeit indirectly). Based on data orthogonal to indirect reports, Kamp and Reyle (1993) reach a similar conclusion. They argue that the "reference time" encoded by the tense should not be held accountable for narrative progression. Only the "reference time" encoded by the aspect should have this function. In the next section, I briefly outline Kamp and Reyle's motivations for such a view and extend their proposed analysis to indirect reports. I show that this analysis has no problems accounting for the indirect report data considered thus far.

\subsection{Kamp and Reyle's analysis of the past tense extended to indirect reports}

Kamp and Reyle (1993) propose that the (simple) past tense is "... ambiguous between (at least) two different relation pairs. When the past tense sentence...[is eventive]...then its tense always corresponds to the pair $<T P p t$ coincides with utterance time; described eventuality before TPpt $>$. When... [the past tense sentence is stative]...the corresponding relations may be $<$ TPpt before the utterance time; described eventuality overlaps TPpt $>$ " (Kamp and Reyle: 597). ${ }^{9}$

\footnotetext{
${ }^{8}$ This assumption is necessary since even if the attitude holder is clueless (or wrong) about what time it is, the bound $t_{0}$ still represents his now and not his past or future. That is, the attitude holder does not believe himself to be living in the past or future of whatever time he may believe it to be (even if he has a false belief about what time it is). See Lewis 1979, and von Stechow 1995 for more discussion of this point.

${ }^{9}$ Kamp and Reyle suggest that the relation imposed by the "eventive" past tense may also be imposed by the "stative" past tense. For the purposes of the paper, this (potential) further ambiguity is not discussed.
} 


$$
\begin{aligned}
& \mathrm{PST}^{1}{ }_{\text {Event }} \leadsto \lambda P_{\varepsilon \oplus \dagger} \lambda w_{l}\left[\exists e_{l}\left[t_{P}{ }^{1}=t_{0} \wedge \tau\left(e_{l}\right)<t_{P}{ }^{1} \wedge P\left(e_{l}\right)\left(w_{l}\right)\right]\right] \\
& \mathrm{PST}^{1}{ }_{\text {State }} \leadsto \lambda R_{\sigma \omega} \lambda \lambda w_{I}\left[\exists s_{I}\left[t_{P}{ }^{1}<t_{0} \wedge t_{P}{ }^{1} \cap \tau\left(s_{l}\right) \neq \varnothing \wedge R\left(s_{l}\right)\left(w_{l}\right)\right]\right]
\end{aligned}
$$

Note that 'TPpt'-represented as $t_{P}$ in the formulas above-corresponds to a perspective time (or temporal perspective point). But what is the nature of a perspective time? It is important to note that Kamp and Reyle's motivations for proposing such a time are quite independent of indirect reports. Due to space limitations, I will only outline one their motivations (see Kamp and Reyle 1993, Chap. 5 for more discussion) and then move on to consider some evidence that Kamp and Reyle provide for the view that the (simple) past tense is ambiguous viz. (22).

Ever since Reichenbach 1947, it has been generally held that temporal interpretation is determined by relating (at least) three distinct times: the reference point (or reference time), the event time and the speech time. This view is made more finegrained in Kamp and Reyle 1993, where it is argued that: "Reichenbach went astray when he wanted his notion of reference point to do too many things at once." Kamp and Reyle observe that in discourses such as (23), which involve the so-called extended flashback, all the past perfect clauses use the time of the arriving as their "reference point." However, these clauses also form a narrative progression and therefore each clause also provides a "reference point" for the clause following it - a time which the eventuality described by the second clause must follow or overlap.

(23) Fred arrived at 10. He had got up at 5; he had taken a long shower, had got dressed and had eaten a leisurely breakfast. He had left the house at 6:30 (Kamp and Reyle 1993: 594).

To account for the temporal ordering in (23), Kamp and Reyle propose that Reichenbach's notion "reference point" should be broken up into two distinct notions, which play entirely different roles. They write:

"We propose to retain the term reference point for the type of reference time which accounts for narrative progression... For reference times that arise in twodimensional analysis of the past perfect, we will use the term temporal perspective point... This term is meant to reflect our intuition that the intermediate time which Reichenbach recognized as essential to the interpretation of past perfects is the time from which the described eventuality is seen as past" (Kamp and Reyle 1993: 594).

Thus in (23), Fred's arrival is the perspective time relative to which all the events denoted by the past perfect predicates are located in time. Moreover, the narrative progression in (23) is accounted for by (2)-(4) and therefore will not be discussed here.

Let us now consider some evidence that Kamp and Reyle provide for the view that the (simple) past tense is ambiguous viz. (22). They observe that in (25) and (26) the adverb now refers to a past interval of time, which serves as the perspective time for and in virtue of which the described eventualities (i.e. feeling at home and writing a letter respectively) are seen as past. 
(25) Mary had been unhappy in her environment for more than a year. But now she felt at home (Kamp and Reyle 1993: 595).

(26) Bill had come home at seven. Now he was writing a letter (Kamp and Reyle 1993: 596).

In contrast to the examples above, (27) shows that now cannot modify eventive sentences in the past tense. This contrast is also evident in Russian (see 28) and in French. ${ }^{10,11}$

(27) \#Bill had come home at seven. Now he wrote a letter (Kamp and Reyle 1993: 596).
Maša čuvstv-ova-l-a
sebja neš̌astnoj $v$ ètoj srede
bol’̌̌se goda.

Masha feel-IPF-PST.3s-FEM self unhappy in this environment more year

No teper'ona (\#po-) čuvstv-ova-l-a sebja zdes' kak doma.

But now she PFV-feel-IPF-PST.3s-FEM self here like home

'Mary had been unhappy in her environment for more than a year. But now she felt at home.'

The data above suggests that the perspective time for an eventive past tense sentence must coincide with the utterance time, while the perspective time for a stative past tense sentence may be some past time that is determined by the context, typically the running time of an eventuality described previously in discourse. If this is right, then the relations between the perspective time and described eventuality imposed by the past tense must be the ones in (22): for eventive sentences, the described eventuality precedes the perspective time (i.e. since the perspective time coincides with the utterance time), while for stative sentences, the described eventuality overlaps the perspective time (i.e. since the perspective time precedes the utterance time). ${ }^{12}$

Let us now apply Kamp and Reyle's analysis of tense to indirect reports. In doing so, I would like to make the following assumption: an embedded past tense is always bound. Given this assumption, let us reconsider the indirect report in (16b), repeated below in (29):

\footnotetext{
${ }^{10}$ Note that the Russian adverb sečas is also translated as 'now'. When this adverb refers to the present moment, it typically co-occurs with perfective predicates (Padučeva 1996). When occurring with an imperfective predicate, this adverb is not deictic (see 37, where it refers to the attitude holder's now) or it has the meaning of "just now" (as in Ja sečas razgovarival s direktorom 'I talked to the director just now'). See Mel'čuk 1985 for an extensive discussion of the difference between sečas and teper'.

${ }^{11}$ Kamp and Reyle point claim that difference between the Passé Simple and the Imparfait in French "roughly corresponds to that between $-S T A T$ and $+S T A T$ [i.e. eventive vs. stative]. The word maintenant ('now') goes with Imparfait but not with Passé Simple" (Kamp and Reyle 1993: 595).

${ }^{12}$ The view that tense is sensitive to the lexical properties of verbs has some cross-linguistic appeal (in addition to the English, Russian and French facts noted above). As argued in Baker and Travis 1998, the Mohawk past tense morpheme hne' can only attach to stative predicates. Future research will hopefully reveal other languages where similar restrictions are found.
} 

a. Dudkin soverši-l ubijstvo v tom zdanii.
Dudkin ${ }^{\mathrm{PFV}}$ committ-PST.3s murder in that building
'Dudkin committed murder in that building.'
b. Mne Anja skazala, čto on y-beža-l s aktrisoj. Me Anna ${ }^{\text {PFV }}$ say-PST.3s that he PFV-run-PST.3s with actress
'Anna told me that he ran away with an actress.'

Recall that (29b) is a problem for the Standard Theory because either it does not rule out an overlapping reading or it derives a contradiction when the reference times in the matrix and the embedded clause are identified. On the other hand, as illustrated by (30), which is a translation of (29b), assuming Kamp and Reyle's meaning for the "eventive" past tense allows us to rule out an overlapping reading even if the reference times in the matrix and the embedded clause are identified. Such is the case because the embedded "eventive" past tense ensures that the running away event precedes the attitude holder's now; see Fig. 5.

$$
\begin{aligned}
& \text { PST }^{1}{ }_{\text {event }} \text { Anja skazat, }{ }^{1} \text { čto } \text { PST }^{2}{ }_{\text {event }} \text { on ubegat }{ }^{2} \leadsto \\
& \lambda w_{I}\left[\exists e _ { I } \left[t_{P}{ }^{1}=t_{0} \wedge \tau\left(e_{1}\right)<t_{P}{ }^{1} \wedge \operatorname{say}\left(\lambda w _ { 2 } \lambda t _ { 0 } \left[\exists e _ { 2 } \left[t_{P}{ }^{2}=t_{0} \wedge \tau\left(e_{2}\right)<t_{P}{ }^{2}\right.\right.\right.\right.\right. \\
& \left.\left.\left.\left.\left.\wedge \operatorname{run} \text {.away }(h e)\left(e_{2}\right)\left(w_{2}\right) \wedge \tau\left(e_{2}\right) \subseteq t_{R}^{2}\right]\right]\right)(\text { anna })\left(e_{1}\right)\left(w_{1}\right) \wedge \tau\left(e_{1}\right) \subseteq t_{R}^{1}\right]\right]
\end{aligned}
$$

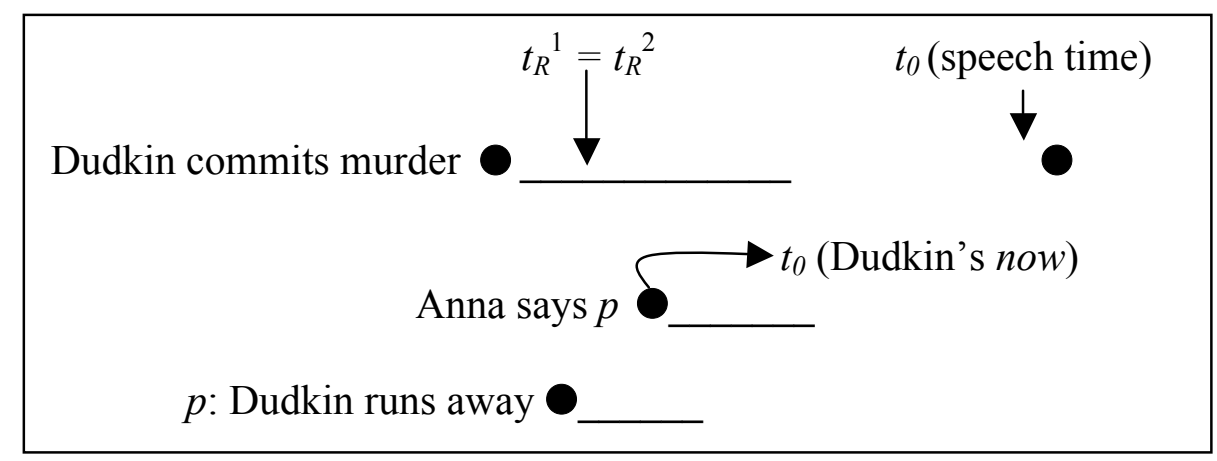

Figure 5: Narrative effects in (29)

By requiring the described event to precede the attitude holder's now, the embedded "eventive" past tense not only accounts for the fact that (29b) entails an non-overlapping reading, but it also prevents the described event from being located in time relative to a reference time that is updated by an indirect speech (or attitude) verb. In this way, the "eventive" past tense overrides the default condition in (4) and thereby accounts for ERT.

What about cases where the embedded predicate is stative? Does the "stative" past tense also override the default condition in (4)? Recall that it requires the described state to overlap a perspective time that is before the local evaluation time $t_{0}$. Fig. 6 and Fig. 7 illustrate the contribution of the embedded "stative" past tense in (5b) and (7b) respectively. Note that I assume that $t_{P}$ in (5b) denotes the time of the speaker filling up Dudkin's glass and the $t_{P}$ in (7b) denotes the time of the speaker's decision: 


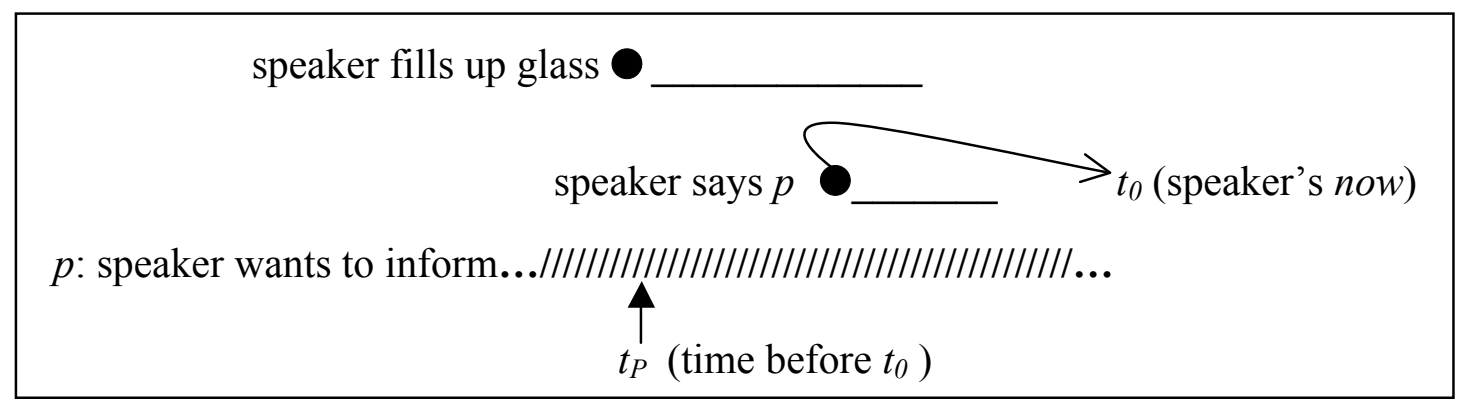

Figure 6: Contribution of the past tense in $(5 \mathrm{~b})$

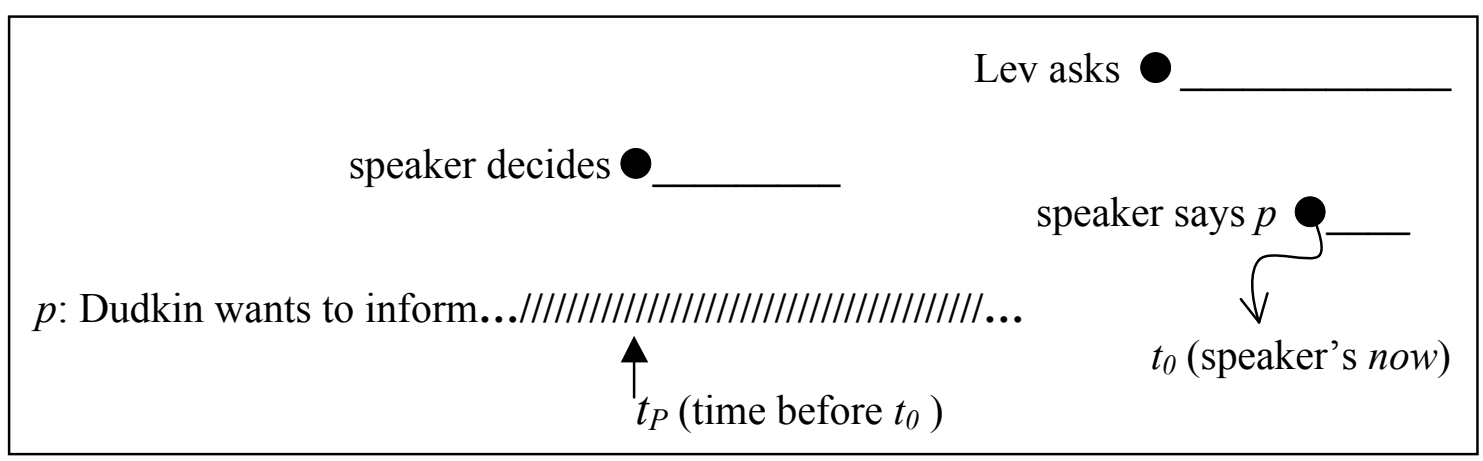

Figure 7: Contribution of the past tense in (7b)

Fig. 6 illustrates that a situation in which the state described by the embedded predicate contains the attitude holder's now is compatible with the requirement imposed by the "stative" past tense. Therefore, unlike the "eventive" past tense, the "stative" past tense does not override the default condition in (4). However, we should not conclude from this that the meaning of the "stative" past tense is inadequate. After all, it allows us to derive the overlapping and the non-overlapping reading in (5b) and (7b) respectively without any additional stipulations. Moreover, it could very well be the case that an embedded past tense overrides the default condition in (4) only when the embedded predicate is eventive; in cases where the embedded predicate is stative, the default condition in (4) is overriden by some other means. Potential evidence for such a view comes from (31b), where the embedded stative predicate does not have past tense morphology (which, in Russian, signals the use of the non-past tense, c.f. the present tense in the English translation) yet we understand the state of Dudkin's house being on fire to hold before the running up event (and continuing to hold throughout this event).

a. Desjat' minut tamu nazad, Dudkin pod-beža-l ko mne $i$ Ten minutes to.that ago, Dudkin PFV-run-PST.3s up.to me and 'Ten minutes ago, Dudkin ran up to me and

b. skaza-l, čto požar v moem dome! ${ }^{\mathrm{PFV}}$ say-PST.1s that fire in my house said that my house is on fire!' 
Since it is highly unlikely that the non-past tense could override the default condition in (4), (31) suggests that this condition is overriden by some other means. If this is right, then a reasonable hypothesis would be to say that whatever overrides the default condition in (31) is also responsible for the override in (5b) and (7b). I leave this issue open for further research.

\section{Conclusion}

In this paper, I have argued that the rules that have been proposed to predict narrative progression in matrix sentences play a crucial role in the temporal ordering of eventualities described by an indirect report. I showed that it automatically follows from (2) that an overlapping reading is entailed by an indirect report with an embedded stative predicate if the reference time in the embedded clause overlaps the time of the matrix eventuality. This generalization is quite different from what has been proposed in the literature on Russian indirect reports. Previous researchers have addressed the question of what allows an embedded eventuality to overlap in time with a matrix eventuality by appealing to properties of grammatical elements such as tense, aspect and verb. I attempted to show how previous generalizations - although incorrect-raise some interesting questions about the temporal interpretation of indirect reports that require further research.

Moreover, I considered what narrative effects in indirect reports reveal about the meaning of the past tense. I presented novel data and argued that a theory which holds that the past tense requires a reference time to precede the local evaluation time (Standard Theory) cannot be right if by "reference time" we mean the topical interval of time previously introduced in discourse that accounts for narrative progression. I argued that a theory of tense that assumes a richer ontology of times - such as the one in Kamp and Reyle 1993-could be extended to account for the indirect report data that the Standard Theory cannot. Many more examples of indirect reports - as they occur within a discourse - need to be considered to see if and how such a theory needs to be refined. The hope is that this paper provides a starting point in this regard.

\section{Appendix: Russian past-under-past indirect reports with an overlapping reading}

Ona duma-l-a, čto Aleksej Aleksandrovič xote-l

She think $\mathrm{IPF}_{\mathrm{IPST}}$-Pp-FEM that Alex Alexandrovich want $_{\mathrm{IPF}}$-PST.3p

čto-to soobščit' ej prijatnoe dlja sebja ob etom dele $i$ ona

something announce her pleasant for self about this matter and she voprosami nave-l-a ego na rasskaz.

questions ${ }^{\mathrm{PFV}}$ point-PST.3p-FEM him to story

'She thought that Alex Alexandrovich wanted to inform her of something about this matter that pleased him, and through questions, she lead him to tell her the story' (Tolstoj, Anna Karenina). 
(33)

Anja zameti-l-a ne bez udivlen'ja, čto kamuški, ležaščie Anna ${ }^{\text {PFV }}$ notice-PST.3s-FEM not without surprise that pebbles lying na polu, odinza drugim prevrašča-l-i-s, $v \quad$ kroxotnye pirožki. on floor one after other change $\mathrm{IPF}_{\mathrm{PP}}$-PST.3p-RFL into small pies "Alice noticed, with some surprise, that the pebbles were all turning into little cakes as they lay on the floor" (Nabakov, Alice in Wonderland; Barensten 1996).

Egoruška, kogda ě̌če ne gore-l kosteri možno by-l-o Egorushka when still not burn IPF-PST.3s fire and possible be $\mathrm{IPF}_{\mathrm{PF}}-\mathrm{PST} .3 \mathrm{~s}-\mathrm{AGR}$ videt' daleko, zameti-l, čto točno takoj-že staryj, pokosivšijsja see IPF-INF far $\quad{ }^{\mathrm{PFV}}$ notice-PST.3s that exactly same old tilt krest stoja-l na drugoj storone bol'šoj dorogi.

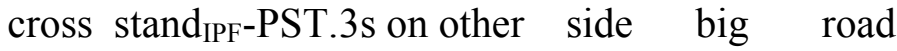
'When the fire was still not burning and it was possible to see afar, Egorushka noticed that the very same, old, tilted cross stood on the other side of the big road' (Chexov, Step'; Costello 1961/62).

V 1915 gody A.C. Buturlin sta-l bolet'. On, kak vrač, In 1915 year A.C. Buturlin ${ }^{\mathrm{PFV}}$ become-PST.3s sick.INF he how doctor ne bez osnovanija predpolaga-l, čto u nego by-l rak. not without basis suspect IPF-PST.3s that to him be $\mathrm{IPF}-$ PST.3s cancer "In 1915, A.C. Buturlin became sick. Being a doctor, he suspected, not without basis for doing so, that he had cancer" (Tolstoy, Očerki bylogo; Costello 1961/62).

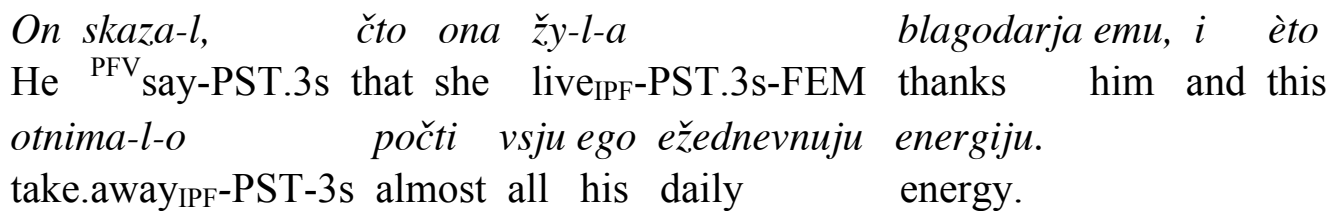
"He said that she was living thanks to him, and that this was taking away almost all of his daily energy" (Mirzuitova, Detstvo s Gurdžievym).

On jasno poni-l, čto sejčas ot nego treb-ova-l-os' He clearly ${ }^{\text {PFV }}$ understand-PST.3s that now from him expect-IPF-PST.3s-RFL tol'ko odno.

only one

"He clearly understood that there was only one thing expected from him now." (Melchuk 1985: 264)

\section{References}

Abusch, Dorit: 1997, 'Sequence of Tense and Temporal De Re', Linguistics and Philosophy 20, 1-50. 
Altshuler, Daniel: 2004, 'A simultaneous perception of things: SOT in Russian', Snippets 8, 5-6.

Babyonyshev, Maria and Ora Matushansky: 2005, 'Back to the past', in J. Lavine, S. Franks, M. Tasseva-Kurktchieva and H. Filip (eds.) Proceedings of FASL 14, Slavic Publications, Michigan University, Ann Arbor.

Baker, Mark and Lisa Travis: 2008, 'Events, Times, and Mohawk Verbal Inflection', Canadian Journal of Linguistics 43, 149-203.

Barensten, Adrian: 1996, 'Shifting points of orientation in Modern Russian: Tense selection in 'reported perception', in Janssen T. and W. van der Wurff (eds.) Reported Speech, John Benjamins, Amsterdam.

Bittner, Maria: 2007, 'Online update: Temporal, modal, and de se anaphora in polysynthetic discourse', in C. Barker and P. Jacobson (eds.), Direct Compositionality, Oxford University Press, Oxford.

Bittner, Maria: 2008, 'Aspectual universals of temporal anaphora', in S. Rothstein (ed.) Theoretical and Crosslinguistic Approaches to the Semantics of Aspect, John Benjamins, Amsterdam.

Boeck, Wolfgang: 1957, 'Zum Tempusgebrauch des Russischen in Objekt- und Subjektsätzen', Zeitschrift für Slavistik 2, 206-218.

Boeck, Wolfgang: 1958, 'Der Tempusgebrauch in den russischen Objekt- und Subjektsätzen, seine historische Entwicklung und sein stilistischer Wert', Zeitschrift für Slavistik: 3, 209-234.

Brasoveanu, Adrian and Donka Farkas: 2007, 'Say reports, Assertion Events and Meaning Dimensions', in A. Cornilescu et al. (eds.) Pitar Mos: A Building with a View. Papers in Honour of Alexandra Cornilescu, Editura Universitatii din Bucuresti, Bucharest.

Brecht, Richard: 1975, 'Relative vs. Absolute Reference in Embedded Tense Forms', Slavic and East European Journal 19, 145-54.

Comrie, Bernard: 1985, Tense, Cambridge University Press, Cambridge.

Comrie, Bernard: 1986, 'Tense in indirect speech', Folia Linguistica 20, 265-296.

Costello, D.P.:1961/62, 'Tenses in Indirect Speech in Russian', Slavonic and East European Review 39, 489-496.

Forbes, Nevill: 1914, Russian Grammar. Oxford University Press.

Forsyth, James: 1970, A Grammar of Aspect: Usage and Meaning in the Russian verbs, Cambridge University Press, Cambridge.

Gennari, Silvia: 2001, 'Tense, aspect and aktionsart in Spanish and Japanese', Maryland Working Papers in Linguistics 11: 60-84.

Gennari, Silvia: 2003, 'Tense meaning and temporal interpretation', Journal of Semantics, 20, 35-71.

Giorgi Alessandra and Fabio Pianesi: 1997, Tense and Aspect. From Semantics to Morphosyntax, Oxford University Press, Oxford.

Heim, Irene: 1994, 'Comments on Abusch's theory of tense', in H. Kamp (ed.), Ellipsis, tense and questions, University of Amsterdam, Amsterdam.

Hinrichs, Erhard: 1981, 'Temporale Anaphora im Englischen', ms., University of Tübingen.

Hinrichs, Erhard: 1986, 'Temporal anaphora in discourses of English', Linguistics and Philosophy 9, 63-82. 
Kamp, Hans: 1979, 'Events, instants and temporal reference', in R. Bäuerle et al (eds.) Semantics from Different Points of View, De Gruyter, Berlin.

Kamp, Hans and Christian Rohrer: 1983, 'Tense in texts', in R. Bäuerle et al (eds.) Meaning, Use and Interpretation of Language, De Gruyter, Berlin.

Kamp, Hans and Uwe Reyle: 1993, From Discourse to Logic: Introduction to Model theoretic Semantics of Natural Language, Formal Logic and Discourse Representation Theory, Kluwer, Dordrecht.

Khomitsevich, Olga: 2008, Dependencies across Phases: From Sequence of Tense to Restrictions on Movement. Doctoral dissertation, Utrecht.

Kondrashova, Natalia: 1998, 'Embedded Tenses in English and Russian', ms., Cornell University, Ithaca.

Kondrashova, Natalia: 2005, 'Is Russian a split SOT-language?' in J. Lavine, S. Franks, M. Tasseva-Kurktchieva and H. Filip (eds.) Proceedings of FASL 14, Slavic Publications, Michigan University, Ann Arbor.

Kusumoto, Kiyomi: 1999, Tense in Embedded Contexts. Doctoral dissertation, University of Massachusetts, Amherst.

Kusumoto, Kiyomi: 2005, 'On the Quantification over Times in Natural Language', Natural Language Semantics 13, 317-357.

Lewis, David: 1979, 'Attitudes De Dicto and De Se', The Philosophical Review 88, 513543.

Link, Godehard: 1987, 'Algebraic Semantics of Event Structures', in J. Groenendijk, M. Stokhof, and F. Veltman (eds.) Proceedings of the Sixth Amsterdam Colloquium, University of Amsterdam, Amsterdam.

Mel'čuk, Igor: 1985, 'Semanticheskie ètjudy i. 'sejchas' i 'teper' v russkom jazyke', Russian Linguistics 9, 257-279.

Padučeva, Elena V.: 1996. Semantichiskie issledovaniya. Yaziky Russkoi Kultury, Moscow.

Partee, Barbara H:. 1984, 'Nominal and Temporal Anaphora', Linguistics and Philosophy 7, 243-286.

Reichenbach, Hans: 1947, Elements of Symbolic Logic, The Macmillan Company, New York.

Schlenker, Philippe: 2003, 'A Plea For Monsters', Linguistics and Philosophy 26, 29120.

Schlenker, Philippe: 2004, 'Sequence Phenomena and Double Access Readings Generalized: Two Remarks on Tense, Person, and Mood', in J. Guéron and J.

Lecarme (eds.) The Syntax of Time, MIT Press, Cambridge.

von Stechow, Arnim: 1995, 'On the proper treatment of tense', in T. Galloway and M. Simons (eds.) Proceedings of SALT V, CLS Publications, Cornell University, Ithaca.

von Stechow, Arnim: 2003, 'Feature deletion under semantic binding: tense, person, and mood under verbal quantifiers', in Kawahara, S. and M. Kadowaki (eds.) Proceeding of NELS 33, BookSurge Publishing.

Webber, Bonnie: 1988, 'Tense as discourse anaphor'. Computational Linguistics 14, 61-73. 